\title{
Peripheral Visual Field Defect
}

National Cancer Institute

\section{Source}

National Cancer Institute. Peripheral Visual Field Defect. NCI Thesaurus. Code C118736.

Reduced or abnormal sight in the peripheral visual field. 